\title{
Atherosclerosis and tumor suppressor molecules (Review)
}

\author{
MIHO SUZUKI*, AKARI MINAMI, ATSUKO NAKANISHI, KEIKO KOBAYASHI, \\ SATORU MATSUDA*, YASUNORI OGURA and YASUKO KITAGISHI \\ Department of Food Science and Nutrition, Nara Women's University, Nishimachi, Nara 630-8506, Japan
}

Received May 26, 2014; Accepted July 18, 2014

DOI: $10.3892 /$ ijmm.2014.1866

\begin{abstract}
Atherosclerosis, the major cause of heart attack and stroke, is a chronic inflammatory disease characterized by the formation of atherosclerotic plaque. Oxidized lowdensity lipoprotein through increased oxidative stress has been identified as one of the primary factors responsible for atherogenesis. Cell proliferation and death are key processes in the progression of atherosclerosis. The oxidative environment in areas of lipid accumulation is mainly created by the production of reactive oxygen species, which are assumed to mediate vascular tissue injury. Oxidative DNA damage and levels of DNA repair are reduced during dietary lipid lowering. The tumor suppressor molecules play a pivotal role in regulating cell proliferation, DNA repair and cell death, which are important processes in regulating the composition of atherosclerotic plaque. Accordingly, in this review, we discuss the fundamental role of tumor suppressor molecules in regulating atherogenesis. In particular, we discuss how tumor suppressor molecules are activated in the complex environment of atherosclerotic plaque, and regulate growth arrest, cell senescence and the apoptosis of vascular smooth muscle cells, which may protect against the progression of atherosclerosis. In addition, we discuss promising alternatives to the use of medications (such as statin) against atherosclerosis, namely diet, with the use of plant-derived supplements to modulate
\end{abstract}

Correspondence to: Professor Satoru Matsuda, Department of Food Science and Nutrition, Nara Women's University, Kita-Uoya Nishimachi, Nara 630-8506, Japan

E-mail: smatsuda@cc.nara-wu.ac.jp

*Contributed equally

Abbreviations: BRAP, BRCA1-associated protein; CDK, cyclindependent kinase; CDK2, cyclin-dependent kinase 2; IL-1 $\beta$, interleukin-1 $\beta$; MDM2, mouse double minute 2 homolog; ox-LDL, oxidized low-density lipoprotein, PTEN, phosphatase and tensin homolog deleted on chromosome $10 ; \mathrm{Rb}$, retinoblastoma tumor suppressor; ROS, reactive oxygen species; SMCs, smooth muscle cells; VECs, vascular endothelial cells; VSMCs, vascular smooth muscle cells

Key words: atherosclerosis, cancer, tumor suppressor, cell signaling, gene expression, medicinal herb the expression and/or activity of tumor suppressor molecules. We also summarize the progress of research made on herbs with a focus on the modulatory roles of tumor suppressors, and on the molecular mechanisms underlying the prevention if atherosclerosis, supporting designs for further research in this field.

\section{Contents}

1. Introduction

2. Association between atherosclerosis and tumor suppressors

3. Activation and inactivation of tumor suppressors involved in atherogenesis

4. Diet-induced expression of tumor suppressors may contribute to vascular protection through the modulation of atherogenesis

5. Perspectives

\section{Introduction}

Atherosclerosis is a systemic disease affecting multiple regions in the arterial wall, which is the primary cause of myocardial infarction, stroke and other peripheral vascular diseases. It is known to be involved in ongoing inflammatory responses and processes (1), and inflammation plays a central role in all phases of atherosclerotic development (2). Thus, atherosclerosis is also a progressive inflammatory disease of the arterial wall (3), which was formerly regarded as a lipid storage disease. In addition to inflammation, the deposition of cholesterol in the arterial wall plays an important role in the pathogenesis of atherosclerosis (4). The condition causes progressive smooth muscle cell (SMC) proliferation and migration that contributes to vascular stenosis (5). Diabetes, obesity and dyslipidemia are primary risk factors for the development of atherosclerosis (6), which are also epidemiologically linked to the increased susceptibility to a various types of cancer (7). The association between obesity and breast cancer, for example, is well established (8). Atherosclerotic plaques grow by the accumulation of inflammatory cells and lipid substances, which is associated with the production of reactive oxygen species (ROS). It has been demonstrated that ROS can interact with cellular DNA to cause DNA strand breaks and/or base modifications (9). These oxidative modifications to DNA may cause a variety of mutations. One of the prominent features of dyslipidemia is the enhanced production of oxidized low-density lipopro- 
tein (ox-LDL), which has been implicated in the key steps of the proliferation of vascular cells and atherogenesis (10). In vascular cells, the internalization of ox-LDL has been shown to trigger signaling events resulting in the overproduction of ROS, inflammation and proliferation (11).

The cellular composition of an atherosclerotic lesion is an important determinant of lesion stability (12). Therefore, the modulation of lesion composition is important in order to reduce the risk of atherosclerotic plaque rupture. Cell proliferation and cell death are key processes in regulating the cellular composition of atherosclerotic lesions (13). Tumor suppressor molecules play a pivotal role in regulating both cell proliferation and cell death in a number of cell types, although different genes also play important roles in the initiation and modulation of atherosclerotic disease through different mechanisms, either through up- or downregulation (14) (Fig. 1). Consequently, tumor suppressor genes involved in regulating cell proliferation and cell death may play an important role in the progression of atherosclerotic lesions, coinciding with changes in cellular composition. For example, the deletion of the tumor suppressor gene, p53, an essential molecule in cell proliferation, DNA repair and apoptosis, strongly exacerbates atherosclerosis (15). In addition, the p53 downstream target, p21WAF1, an inhibitor of cell cycle progression through the inactivation of cyclin-cyclin-dependent kinase (CDK) complexes during the G1 phase of the cell cycle, has proatherogenic functions (16). These data indicate the important role of tumor suppressor molecules in controlling atherogenesis. In this review, the association between atherosclerosis and certain tumor suppressor molecules is summarized with focus on the pathogenesis of atherosclerosis, which would essentially facilitate more effective treatments for a better prognosis.

\section{Association between atherosclerosis and tumor suppressors}

The proliferation of vascular smooth muscle cells (VSMCs) contributes to a variety of pathological states including atherosclerosis (17). Cell invasion of the extracellular matrix is essential for the cross tissue migration of VSMCs in atherosclerosis (18). The tumor suppressor, p53, has gained attentiondue to its additional function as a suppressor of cell migration and invasion. p53 also facilitates the apoptosis of VSMCs and is involved in the ox-LDL-induced apoptosis of macrophages (19). As much of the genotoxic stress response flows through the p53 pathway, p53 is considered to play an important role in the effects of genotoxic stress. Furthermore, DNA damage disorders caused by mutations in genotoxic stress-response genes are characterized by atherosclerosis (Fig. 1). p53 is ubiquitously expressed in all cell types as an inactive transcription factor which undergoes activation in response to various types of cellular stress. Evidence has implicated p53 as a regulator of pathological vascular remodeling (20). The effects of p53 are mediated through different downstream effectors and targets. Among these, the CDK inhibitor, p21WAF1, is a key mediator of p53 action, which may be involved in monocyte and dendritic cell differentiation (21). There is substantial evidence that $\mathrm{p} 21 \mathrm{WAF} 1$ also participates in the protective effects of p53 on atherosclerosis (22). Generally, p21WAF1 is considered as a potential therapeutic gene that may be used to treat or prevent atherosclerosis. p21WAF1 regulates cell-cycle progression, senescence and differentiation in injured blood vessels, which may function to prevent atherogenesis by regulating the redox balance, which leads to the inhibition of adhesion molecules (23). The CDK inhibitor, p27KIP1, also regulates cell proliferation, vascular remodeling and inhibits atherosclerosis. While the expression of tissue factors is a key initiator of the coagulation cascade associated with atherosclerosis, p27KIP1 inhibits tissue factor expression at the transcriptional level (24). In addition, a single nucleotide polymorphism $(838 \mathrm{C}>\mathrm{A})$ in the $\mathrm{p} 27 \mathrm{KIP} 1$ gene is associated with a commonly encountered genetic variant associated with therapeutic cardiovascular interventions (25). Furthermore, the inactivation of p27KIP1 has been shown to exacerbate atherosclerosis in a mouse model (26). Minocycline has been shown to reduce plaque size and stenosis in diet-induced atherosclerosis through increased p27KIP1 expression in a mouse model (27).

The residue-specific phosphorylation profile of the retinoblastoma tumor suppressor $(\mathrm{Rb})$ appears to differ between the internal mammary artery and coronary artery (28). The differential profile of $\mathrm{Rb}$ phosphorylation may be a consequence of variances in the content of the CDK2 and CDK4 phosphorylation inhibitor, p15INK4. siRNA-mediated CDK2 knockdown modifies the profile of $\mathrm{Rb}$ phosphorylation in VSMCs of the coronary artery, as well as the proliferative response of these cells to mitogenic stimulation $(28,29)$. The intrinsic functional and protein composition specificity of the VSMC population in the coronary artery may contribute to the increased incidence of atherosclerosis in the arteries. In fact, foam cell formation is induced through increased $\mathrm{Rb}$ phosphorylation (30). Apolipoprotein E (ApoE)-deficient mice lacking macrophage $\mathrm{Rb}$ display accelerated atherosclerosis coinciding with increased macrophage proliferation, suggesting that macrophage $\mathrm{Rb}$ is a suppressive factor in the progression of atherosclerosis by reducing macrophage cell proliferation (31). The phosphatase and tensin homolog deleted on chromosome 10 (PTEN)/AKT signaling pathway has also been implicated in the pathogenesis of vascular diseases. PTEN is a dual-specificity phosphatase that has been shown to inhibit VSMC proliferation and migration (32). Genetic research has demonstrted that the PTEN gene is critical to the pathological development of atherosclerosis (33). In addition, elevated PTEN expression and concomitant AKT inactivation have been observed in the endothelium of atherosclerotic arteries (34). The PTEN pathway may be important in the regulation of the inflammatory response in VSMCs. The tumor suppressor breast cancer 1 , early onset (BRCA1) gene implicated in the development of breast and ovarian cancers exerts multiple effects on DNA repair and affords resistance against cellular stress responses (35), which is basally expressed in endothelial cells. BRCA1 may be a gatekeeper of inflammation-induced endothelial cell function $(36,37)$. Whereas BRCA1 silencing exaggerates inflammation-induced endothelial cell apoptosis, BRCA1 overexpression protects cells againts this. BRCA1 overexpression intensely attenuates the production of ROS, upregulating endothelial nitric oxide synthase and vascular endothelial growth factor expression. BRCA1 expression is attenuated in the plaque region of human atherosclerotic arteries. It has been shown that single nucleotide polymorphisms (SNPs) in the BRCA1-associated protein (BRAP) gene 


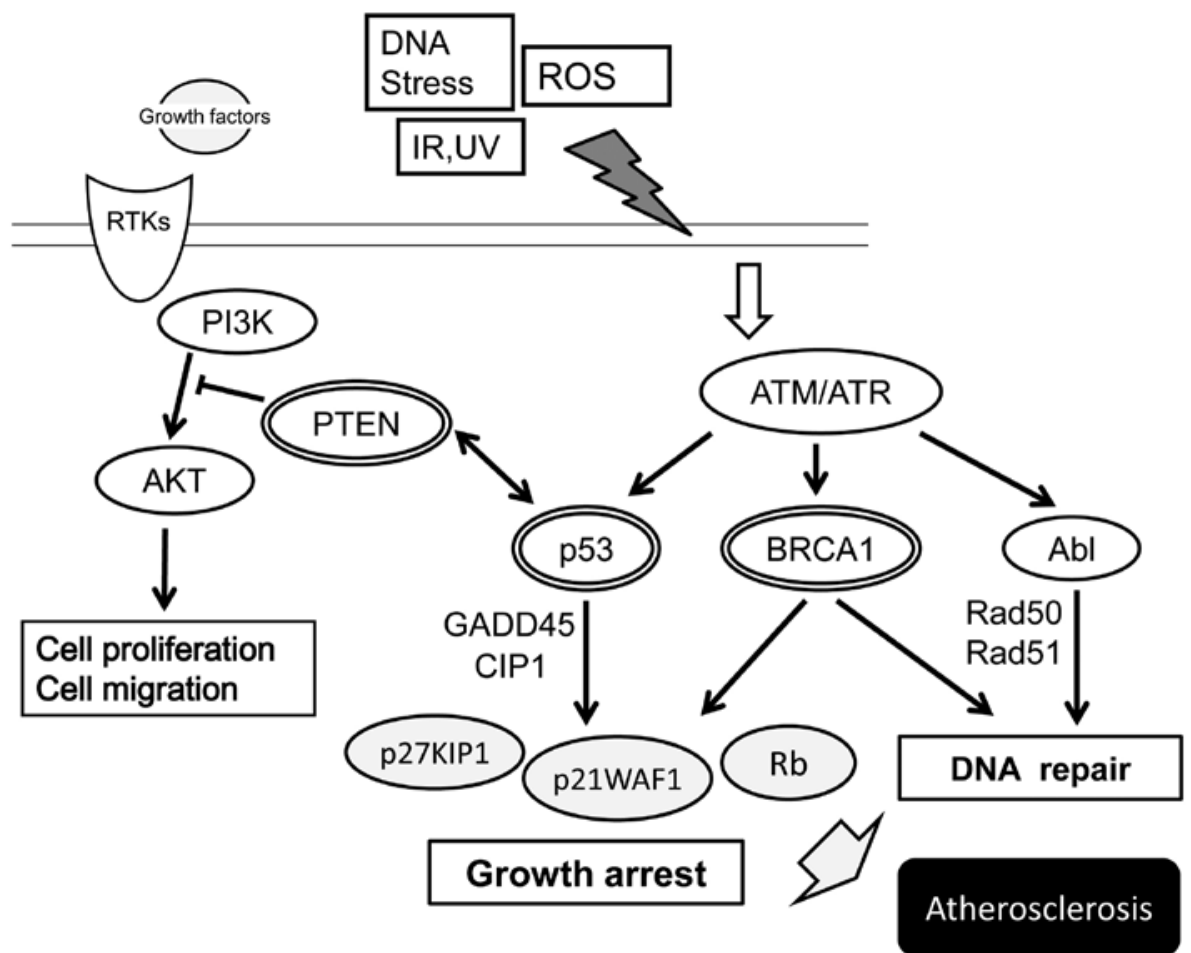

Figure 1. Schematic representation of tumor suppressor signaling including p53, retinoblastoma tumor suppressor (Rb), p21WAF1/p27KIP1, phosphatase and tensin homolog deleted on chromosome 10 (PTEN) and breast cancer 1, early onset (BRCA1). Examples of molecules involved in atherogenesis known to act on cell proliferation, cell migration, cell growth arrest and DNA repair through the regulatory pathways are shown. Note that some critical pathways have been omitted for clarity. RTKs, receptor tyrosine kinases; PI3K, phosphoinositide 3-kinase; ROS, reactive oxygen species; ATM/ATR, ataxia telangiectasia mutated/ ataxia telangiectasia.

are associasted with the risk of myocardial infarction in a large cohort (38).

\section{Activation and inactivation of tumor suppressors involved in atherogenesis}

Again, cell proliferation and cell death are important processes in regulating macrophage and VSMC numbers in the atherosclerotic lesion, which may directly influence lesion stability. Atherosclerosis is initiated by the subendothelial accumulation of cholesterol-engorged macrophages (39). Atherosclerotic plaques contain $\beta$-Gal-positive vascular endothelial cells (VECs) and VSMCs exhibit the morphological features of senescence. It has also been reported that interleukin-1 $\beta$ (IL-1 $\beta$ ) is expressed in senescent cells located in human atherosclerotic lesions, suggesting that senescent cells may promote inflammation in lesions (40). Tumor suppressor molecules regulate diverse cellular activities, including DNA damage repair, cell proliferation, cell differentiation, cell migration, cellular senescence and programmed cell death (Fig. 1). An important tumor suppressor is the p53 tumor suppressor. Other examples of tumor suppressors, include Rb, PTEN, p21WAF1, p27KIP1 and BRCA1 (Fig. 2) (18). Various cell proliferation- and apoptosissignal transduction pathways are built on complex networks between oncogenes and tumor suppressor genes, such as p53 and its downstream factors. For example, the tumor suppressor p53 regulates the expression of various genes and plays an important role in cell proliferation and in the modulation of signal transduction pathways (41). The accumulation of p53 in cells following DNA damage leads to cell cycle arrest and the induction of apoptosis. In addition, p53 is involved in the repair of damaged DNA and thus prevents the accumulation of mutations and suppresses tumor development (42). There are two types of p53 genes, the wild-type p53 gene and the mutant p53 gene (43). Oncogenic p53 mutations usually confer the mutant protein with a dominant-negative activity over the remaining wild-type gene. Many mutant p53 forms acquire dominant-negative activities, and sometimes gain oncogenic properties (43). These activities of p53 are also regulated by post-translational modification (44). The phosphorylation and acetylation state, subcellular localization and interaction with other cellular proteins are likely to influence the function of p53 (45). In cells facing oxidative stress and DNA-damage, p53 dissociates from its ubiquitin ligase mouse double minute 2 homolog (MDM2) (46), through various post-translational modifications which promote its stabilization.

Functional studies have linked p53 with proliferative vascular disease. Arterial p53 inactivation following human cytomegalovirus infection may contribute to coronary restenosis (47). In addition, p53-null mice are susceptible to atherosclerosis (48). However, the role of p53 in VSMC proliferation and apoptosis in atherosclerosis is somewhat controversial. Cell-specific p53 deficiency worsens the progression of atheroma in animal models of diet-induced atherosclerosis (49). The induction of p53 during ischemia has been shown to contribute to tissue damage through the activation of apoptosis. By contrast, the temporary inhibition of p53 function may be beneficial to the prevention of injury to diverse 
p53
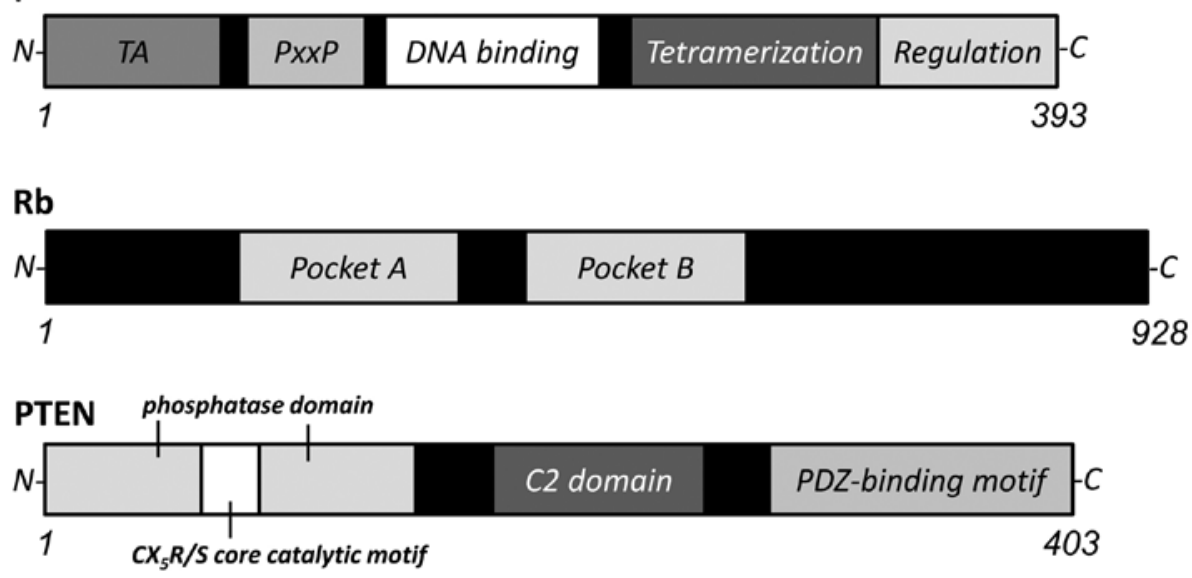

BRCA1

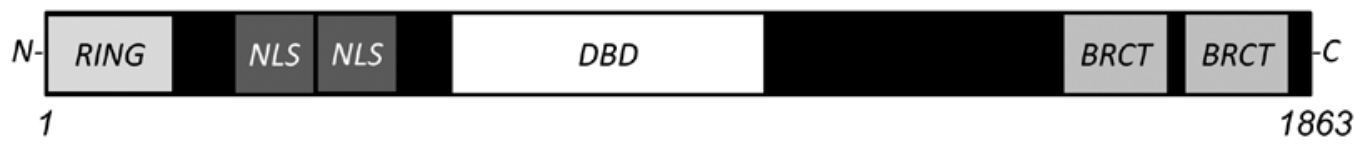

Figure 2. Schematic structures of p53, retinoblastoma tumor suppressor (Rb), phosphatase and tensin homolog deleted on chromosome 10 (PTEN) and breast cancer 1, early onset (BRCA1) protein. The predicted consensual domain structures for each protein are depicted. The functionally important sites are also shown. Note that the sizes of proteins are modified for clarity. TA, transactivation domain; PxxP, proline-rich region; Pocket A, Pocket B, a tandem of folds; C2 domain, a protein structural domain involved in targeting proteins to cell membranes; PDZ, a common structural domain in signaling proteins (PSD95, Dlg, ZO-1. etc.); RING, really interesting new gene finger domain; NLS, nuclear localization signal; DBD, DNA binding domain; BRCT, BRCA1 C terminus.

organs (50) or in the treatment of myocardial infarction (51). p53 may act to promote cell death or survival depending on the cell type, gene expression profile, protein activity and the type of stress stimuli (52). In addition to $\mathrm{p} 53$, a number of cell cycle regulators modulate $\mathrm{Rb}$ function through its phosphorylation status. Hypo-phosphorylated wild-type $\mathrm{Rb}$ is tightly bound to the nuclear matrix and seems to be critical in the inhibition of cellular proliferation (53). By contrast, hyper-phosphorylation is a physiological mechanism of the inactivation of $\mathrm{Rb}$. Active complexes of G1 cyclins and CDKs inactivate Rb through its phosphorylation (54), while p21WAF1 and p27KIP1 inhibit CDKs. As reversible phosphorylation plays a fundamental role in regulating intracellular signaling, dysregulation of the mechanisms that regulate phosphorylation may also play a role in the initiation and maintenance of atherosclerosis.

The adenoviral vector-mediated delivery of the p21WAF1 gene to the vessel wall has been shown to protect arteries against the development of intimal hyperplasia (55), which also protects against restenosis in ApoE-deficient mice by reducing VSMC proliferation and macrophage infiltration (56). However, it has been shown that p21WAF1 may also be a proatherogenic molecule. The inactivation of p21WAF1 appears to protect against atherosclerosis, inhibiting lesion growth and promoting its stability. Therapies that target p21WAF1 for inactivation in the appropriate situation may offer protection against atherosclerosis (57). PTEN upregulation induces endothelial dysfunction by attenuating the availability and signaling of multiple angiogenic pathways in VSMCs $(34,58)$. However, adenovirus-mediated PTEN overexpression inhibits the formation of vascular obstructive lesions induced by mechanical injury. BRCA1 overexpression develops less aortic plaque lesions, exhibits reduced macrophage infiltration, and generates less ROS (36,59). Aortic segments from BRCAl(-/-) mice have demonstrated more inflammation-associated apoptosis and impaired endothelial function $(36,59)$. Mainly, the above-mentioned tumor suppressor molecules may be regulators of systemic lipid homeostasis and of the development of atherosclerosis.

\section{Diet-induced expression of tumor suppressors may contribute to vascular protection through the modulation of atherogenesis}

Potential therapeutic strategies exploit the observation that defects in critical processes required for maintaining cellular homeostasis produce a metabolic situation characterized by atherosclerosis $(48,60)$. It has been reported that the free cholesterol loading of macrophages induces apoptosis in atherosclerosis and that apoptosis decreases after lipid lowering (61). In addition, the nutritional control of gene regulation guides the transformation of VSMCs into foam cells in atherosclerosis. Actually, several gene transcriptions are regulated by dietary polyunsaturated fatty acids (62). Apoptosis in VSMCs can be promoted by the deregulation of tumor suppressor molecules. Furthermore, VSMCs in atherosclerotic plaques may be lost through the apoptosis, increasing the risk of thrombosis. As p53 deficiency leads to a substantial doubling of atherosclerotic lesion size, it may be speculated that diets that stimulate p53 expression in macrophages may lead to a reduction in atherosclerosis (63). Therefore, it would be important to define appropriate strategies to achieve benefits from diet to control the expression of tumor suppressor molecules.

The medicinal herb, Gleditsia sinensis thorns, has been shown to induce an increase in cell cycle arrest during the 


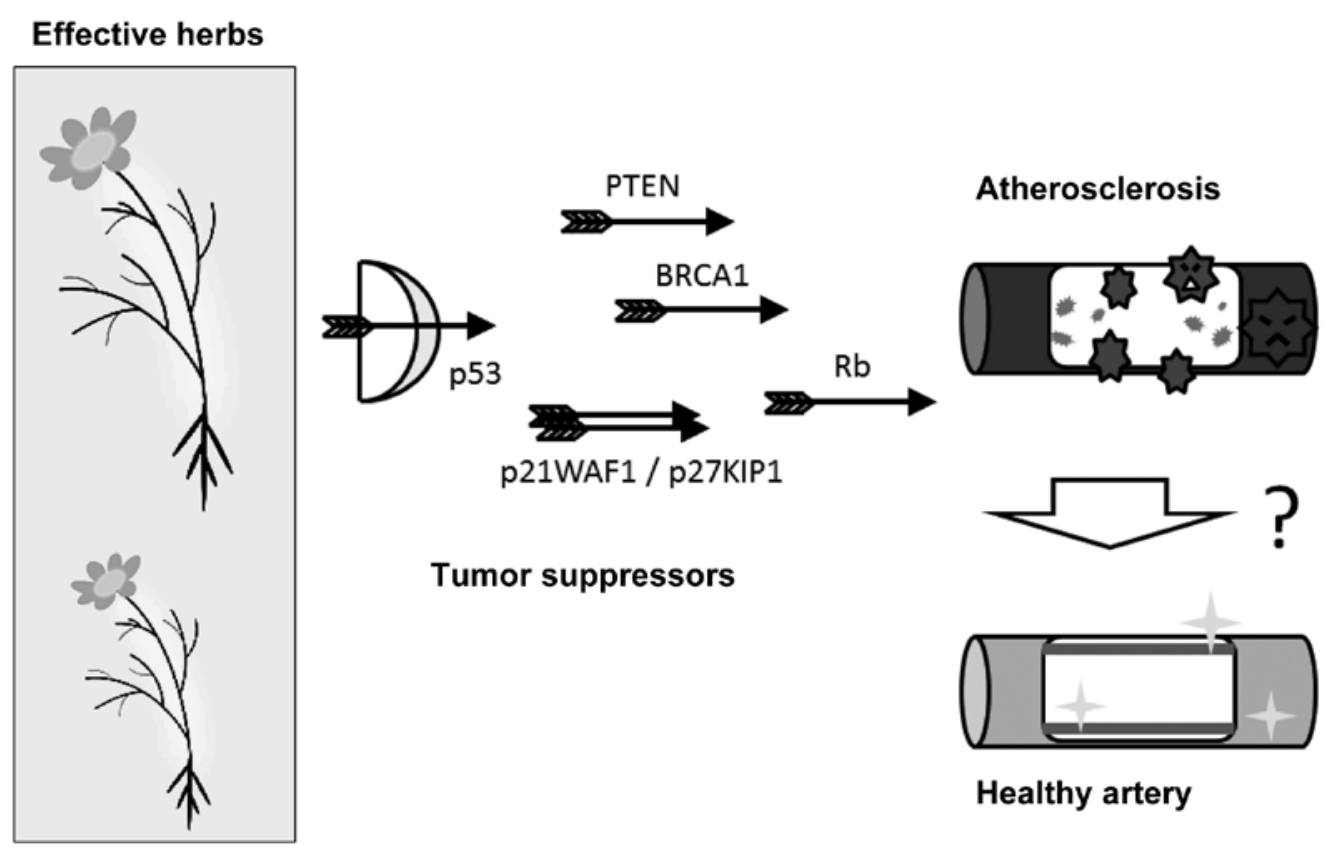

Figure 3. Tumor suppressor-dependent anti-atherosclerotic function of medicinal herbs. Schematic illustrations of the tentative model for the anti-atherosclerotic function of herbs are shown. Herbs can stimulate tumor suppressor molecule expression and/or activities against atherosclerosis, which can also contribute to the prevention of atherosclerosis.

G2/M phase, being associated with increased p53 levels (64). Treatment with the ethanol extract of Gleditsia sinensis thorns in VSMCs has been shown to be associated with upregulated p21WAF1 levels (65). Both p53 and p21WAF1mRNA levels increase with the use of Kanglaite, an extract from Coix seed. Kanglaite appears to extend the half-life of the p53 protein (66). Ginsenoside, one of the components in the American ginseng herb, has been shown to activate p53 (67). In addition, the induction of apoptosis by thymoquinone, the most abundant component in black seed, has been shown to be associated with an increase in p53 mRNA expression and downstream p53 target genes (68). Treatment with Magnolia officinalis extract has been shown to upregulate the expression of p21WAF1 and p27 KIP1 (69). A herb-derived flavonoid compound, Baicalin, enhances the expression of p27 Kip1 (70). Treatment with the ethyl acetate extract of Saussurea involucrata has been shown to induce p21WAF1 and p27KIP1 expression, independent of the p53 pathway (71). Treatment with honokiol, a component of the oriental herb, Magnolia officinalis, has been shown to exert a marked decrease in the levels of Rb protein (72). Triptolide, a purified extract from the herb Tripterygium wilfordii Hook F has been shown to increase p21WAF1 expression and reduce $\mathrm{Rb}$ phosphorylation (73). Acanthopanax gracilistylus, a medicinal herb, decreases the levels of phosphorylated $\mathrm{Rb}$ protein (74). Licochalcone and dichloromethane from cape aloe extract also inhibit the phosphorylation of the $\mathrm{Rb}$, specifically at the S780 phosphorylation site $(75,76)$. In addition, the multiherb anti-inflammatory product, Zyflamend, downregulates the phosphorylation of $\mathrm{Rb}$ (77). Honokiol has been demonstrated to attenuate the angiogenic activities of human endothelial cells, which can attenuate phosphoinositide 3-kinase (PI3K)/AKT signaling through the upregulation of PTEN expression $(78,79)$. Curcumin, an active ingredient derived from the root of the plant Curcuma longa, restores PTEN expression (80). By contrast, some components of the Rosemary herb have been shown to inhibit the expression of PTEN in K562 myeloid cell line cells (81). Soy phytoestrogens, such as genistein and daidzein decrease DNA methylation in BRCA1 gene (82).

It will be a challenge to seek out how to use these medicinal herbs for the correction in critical processes required for maintaining cellular homeostasis linked to a metabolic situation characterized by atherosclerosis (Fig. 3).

\section{Perspectives}

Atherosclerosis is likely to dominate clinical practice for decades. The information presented herein may provide further insight into the molecular mechanisms underlying the clinical use of herbs as a therapy for atherosclerosis. The identification of target molecules relevant for atherosclerosis allows screening for natural products capable of modulating targets. This may also represent the basis for the development of rational dietary treatment of other diseases. Future studies are required to demonstrate whether tumor suppressors and/or their downstream targets can be used to modulate the cellular composition of plaques, thereby enhancing plaque stability. Atherosclerosis is caused by a number of factors, including oxidative stress which increases sphingomyelinase and ceramides correlated with the level of ox-LDL (83). During atherogenesis, ROS are formed, resulting in oxidative DNA damage which is followed by increased DNA repair activity so that initial damage is effectively repaired. Tumor suppressors are key molecules at this point. Further studies are required to elucidate the potential roles of damaged DNA in the pathogenesis of atherosclerosis. Further understanding of the local determinants of the phenotype of endothelial cells in the lesion and how they interact with atherosclerosis risk factors may lead to a notable improvement in therapies. 


\section{Acknowledgements}

This study was supported by Grants-in-Aid from the Ministry of Education, Culture, Sports, Science and Technology in Japan.

\section{References}

1. Libby P: Inflammation in atherosclerosis. Nature 420: $868-874$, 2002.

2. Spagnoli LG, Bonanno E, Sangiorgi G and Mauriello A: Role of inflammation in atherosclerosis. J Nucl Med 48: 1800-1815, 2007.

3. Curtiss LK and Tobias PS: The toll of Toll-like receptors, especially toll-like receptor 2 , on murine atherosclerosis. Curr Drug Targets 8: 1230-1238, 2007.

4. Cicchi R, Matthäus C, Meyer T, Lattermann A, Dietzek B, Brehm BR, Popp J and Pavone FS: Characterization of collagen and cholesterol deposition in atherosclerotic arterial tissue using non-linear microscopy. J Biophotonics 7: 135-143, 2014.

5. Pakala R, Rha SW, Kuchulakanti PK, Cheneau E, Baffour R and Waksman R: Peroxisome proliferator-activated receptor gamma Its role in atherosclerosis and restenosis. Cardiovasc Radiat Med 5: 44-48, 2004.

6. Bays HE: Adiposopathy, diabetes mellitus, and primary prevention of atherosclerotic coronary artery disease: treating 'sick fat' through improving fat function with antidiabetes therapies. Am J Cardiol 110: B4-B12, 2012.

7. Blüher M: Adipose tissue dysfunction in obesity. Exp Clin Endocrinol Diabetes 117: 241-250, 2009.

8. Stoll BA: Western nutrition and the insulin resistance syndrome: a link to breast cancer. Eur J Clin Nutr 53: 83-87, 1999.

9. Kligerman AD, Malik SI and Campbell JA: Cytogenetic insights into DNA damage and repair of lesions induced by a monomethylated trivalent arsenical. Mutat Res 695: 2-8, 2010.

10. Lin FY, Lin YW, Huang CY, Chang YJ, Tsao NW, Chang NC, Ou KL, Chen TL, Shih CM and Chen YH: GroEL1, a heat shock protein 60 of Chlamydia pneumoniae, induces lectin-like oxidized low-density lipoprotein receptor 1 expression in endothelial cells and enhances atherogenesis in hypercholesterolemic rabbits. J Immunol 186: 4405-4414, 2011.

11. Dai Y, Mercanti F, Dai D, Wang X, Ding Z, Pothineni NV and Mehta JL: LOX-1, a bridge between GLP-1R and mitochondrial ROS generation in human vascular smooth muscle cells. Biochem Biophys Res Commun 437: 62-66, 2013.

12. Dickhout JG, Basseri S and Austin RC: Macrophage function and its impact on atherosclerotic lesion composition, progression, and stability: the good, the bad, and the ugly. Arterioscler Thromb Vasc Biol 28: 1413-1415, 2008.

13. Edlin RS, Tsai S, Yamanouchi D, Wang C, Liu B and Kent KC: Characterization of primary and restenotic atherosclerotic plaque from the superficial femoral artery: potential role of Smad3 in regulation of SMC proliferation. J Vasc Surg 49: 1289-1295, 2009.

14. Humphries SE and Ordovas JM: Genetics and atherosclerosis: broadening the horizon. Atherosclerosis 154: 517-519, 2001.

15. Mercer J and Bennett M: The role of p53 in atherosclerosis. Cell Cycle 5: 1907-1909, 2006.

16. Khanna AK: Enhanced susceptibility of cyclin kinase inhibitor p21 knockout mice to high fat diet induced atherosclerosis. J Biomed Sci 15: 16-66, 2009.

17. Heusch G, Libby P, Gersh B, Yellon D, Böhm M, Lopaschuk G and Opie L: Cardiovascular remodelling in coronary artery disease and heart failure. Lancet 383: 1933-1943, 2014.

18. Mak AS: p53 in cell invasion, podosomes, and invadopodia. Cell Adh Migr: Feb 18, 2014 (Epub ahead of print).

19. Ishii N, Matsumura T, Kinoshita H, Motoshima H, Kojima K, Tsutsumi A, Kawasaki S, Yano M, Senokuchi T, Asano T, Nishikawa T and Araki E: Activation of AMP-activated protein kinase suppresses oxidized low-density lipoprotein-induced macrophage proliferation. J Biol Chem 284: 34561-34569, 2009.

20. Anderson JL, Ashwell CM, Smith SC, Shine R, Smith EC and Taylor RL Jr: Atherosclerosis-susceptible and atherosclerosisresistant pigeon aortic cells express different genes in vivo. Poult Sci 92: 2668-2680, 2013

21. Liu WM, Scott KA, Thompson M and Dalgleish AG: Dendritic cell phenotype can be improved by certain chemotherapies and is associated with alterations to $\mathrm{p} 21$ (waf1/cip1.). Cancer Immunol Immunother 62: 1553-1561, 2013.
22. Kim HJ, Yoo EK, Kim JY, Choi YK, Lee HJ, Kim JK, Jeoung NH, Lee KU, Park IS, Min BH, Park KG, Lee CH, Aronow BJ, Sata M and Lee IK: Protective role of clusterin/apolipoprotein J against neointimal hyperplasia via antiproliferative effect on vascular smooth muscle cells and cytoprotective effect on endothelial cells. Arterioscler Thromb Vasc Biol 29: 1558-1564, 2009.

23. Obikane H, Abiko Y, Ueno H, Kusumi Y, Esumi M and Mitsumata M: Effect of endothelial cell proliferation on atherogenesis: a role of $\mathrm{p} 21(\mathrm{Sdi} / \mathrm{Cip} / \mathrm{Waf} 1)$ in monocyte adhesion to endothelial cells. Atherosclerosis 212: 116-122, 2010.

24. Breitenstein A, Akhmedov A, Camici GG, Lüscher TF and Tanner FC: p27(Kip1) inhibits tissue factor expression. Biochem Biophys Res Commun 439: 559-563, 2013.

25. Conte MS, Owens CD, Belkin M, Creager MA, Edwards KL, Gasper WJ, Kenagy RD, LeBoeuf RC, Sobel M and Clowes A: A single nucleotide polymorphism in the p27(Kip1) gene is associated with primary patency of lower extremity vein bypass grafts. J Vasc Surg 57: 1179-1185, 2013.

26. Díez-Juan A, Pérez P, Aracil M, Sancho D, Bernad A, SánchezMadrid F and Andrés V : Selective inactivation of p27(Kip1) in hematopoietic progenitor cells increases neointimal macrophage proliferation and accelerates atherosclerosis. Blood 103: 158-161, 2004.

27. Shahzad K, Thati M, Wang H, Kashif M, Wolter J, Ranjan S, He T, Zhou Q, Blessing E, Bierhaus A, Nawroth PP and Isermann B: Minocycline reduces plaque size in diet induced atherosclerosis via p27(Kip1). Atherosclerosis 219: 74-83, 2011.

28. Lange M, Fujikawa T, Koulova A, Kang S, Griffin MJ, Lassaletta AD, Erat A, Tobiasch E, Bianchi C, Elmadhun N, Sellke FW and Usheva A: Arterial territory-specific phosphorylated retinoblastoma protein species and CDK2 promote differences in the vascular smooth muscle cell response to mitogens. Cell Cycle 13: 315-323, 2014.

29. Faber AC and Chiles TC: Inhibition of cyclin-dependent kinase-2 induces apoptosis in human diffuse large B-cell lymphomas. Cell Cycle 6: 2982-2989, 2007.

30. Ma KL, Liu J, Wang CX, Ni J, Zhang Y, Wu Y, Lv LL, Ruan XZ and Liu BC: Activation of mTOR modulates SREBP-2 to induce foam cell formation through increased retinoblastoma protein phosphorylation. Cardiovasc Res 100: 450-460, 2013.

31. Boesten LS, Zadelaar AS, van Nieuwkoop A, Hu L, Jonkers J, van de Water B, Gijbels MJ, van der Made I, de Winther MP, Havekes LM and van Vlijmen BJ: Macrophage retinoblastoma deficiency leads to enhanced atherosclerosis development in ApoE-deficient mice. FASEB J 20: 953-955, 2006.

32. Chen WJ, Lin KH, Lai YJ, Yang SH and Pang JH: Protective effect of propylthiouracil independent of its hypothyroid effect on atherogenesis in cholesterol-fed rabbits: PTEN induction and inhibition of vascular smooth muscle cell proliferation and migration. Circulation 110: 1313-1319, 2004.

33. Yuan M, Wang X, Zhan Q, Duan X, Yang Q and Xia J: Association of PTEN genetic polymorphisms with atherosclerotic cerebral infarction in the Han Chinese population. J Clin Neurosci 19: $1641-1645,2012$.

34. Kuo HM, Lin CY, Lam HC, Lin PR, Chan HH, Tseng JC, Sun CK, Hsu TF, Wu CC, Yang CY, Hsu CM and Tai MH: PTEN overexpression attenuates angiogenic processes of endothelial cells by blockade of endothelin-1/endothelin B receptor signaling. Atherosclerosis 221: 341-139, 2012.

35. Bae I, Fan S, Meng Q, Rih JK, Kim HJ, Kang HJ, Xu J, Goldberg ID, Jaiswal AK and Rosen EM: BRCA1 induces antioxidant gene expression and resistance to oxidative stress. Cancer Res 64: 7893-7909, 2004.

36. Singh KK, Shukla PC, Quan A, Al-Omran M, Lovren F, Pan Y, Brezden-Masley C, Ingram AJ, Stanford WL, Teoh H and Verma S: BRCA1 is a novel target to improve endothelial dysfunction and retard atherosclerosis. J Thorac Cardiovasc Surg 146: 949-960, 2013.

37. Lovren F, Pan Y, Quan A, Singh KK, Khan R, Gupta N, BrezdenMasley C, Teoh H, Wheatcroft MD, Al-Omran M and Verma S: BRCA1 shields vascular smooth muscle cells from oxidative stress. J Thorac Cardiovasc Surg 147: 1946-1955, 2014.

38. Ozaki K, Sato H, Inoue K, Tsunoda T, Sakata Y, Mizuno H, Lin TH, Miyamoto Y, Aoki A, Onouchi Y, Sheu SH, Ikegawa S, Odashiro K, Nobuyoshi M, Juo SH, Hori M, Nakamura Y and Tanaka T: SNPs in BRAP associated with risk of myocardial infarction in Asian populations. Nat Genet 41: 329-333, 2009.

39. Jerome WG: Lysosomes, cholesterol and atherosclerosis. Clin Lipidol 5: 853-865, 2010. 
40. Suzuki E, Takahashi M, Oba S and Nishimatsu H: Oncogeneand oxidative stress-induced cellular senescence shows distinct expression patterns of proinflammatory cytokines in vascular endothelial cells. ScientificWorldJournal 2013: 754735, 2013.

41. Boominathan L: The guardians of the genome (p53, TA-p73, and TA-p63) are regulators of tumor suppressor miRNAs network. Cancer Metastasis Rev 29: 613-639, 2010.

42. O'Neil N and Rose A: DNA repair. WormBook 1-12, 2006

43. Muller PA and Vousden KH: 53 mutations in cancer. Nat Cell Biol 15: 2-8, 2013

44. Conforti F, Sayan AE, Sreekumar R and Sayan BS: Regulation of 73 activity by post-translational modifications. Cell Death Dis 3: e285, 2012 .

45. Appella E and Anderson CW: Post-translational modifications and activation of p53 by genotoxic stresses. Eur J Biochem 268: 2764-2772, 2001.

46. Hock AK and Vousden KH: The role of ubiquitin modification in the regulation of p53. Biochim Biophys Acta 1843: 137-149, 2014

47. Mattila KJ, Valtonen VV, Nieminen MS and Asikainen S: Role of infection as a risk factor for atherosclerosis, myocardial infarction, and stroke. Clin Infect Dis 26: 719-734, 1998.

48. Razani B, Feng C and Semenkovich CF: p53 is required for chloroquine-induced atheroprotection but not insulin sensitization. J Lipid Res 51: 1738-1746, 2010.

49. Martinet W, Knaapen MW, De Meyer GR, Herman AG and Kockx MM: Oxidative DNA damage and repair in experimental atherosclerosis are reversed by dietary lipid lowering. Circ Res 88: 733-739, 2001

50. Georgiev P, Dahm F, Graf R and Clavien PA: Blocking the path to death: anti-apoptotic molecules in ischemia/reperfusion injury of the liver. Curr Pharm Des 12: 2911-2921, 2006.

51. Matsusaka H, Ide T, Matsushima S, Ikeuchi M, Kubota T, Sunagawa K, Kinugawa S and Tsutsui H: Targeted deletion of p53 prevents cardiac rupture after myocardial infarction in mice. Cardiovasc Res 70: 457-465, 2006.

52. Kim YC, Kitaura H, Taira T, Iguchi-Ariga SM and Ariga $\mathrm{H}$ : Oxidation of DJ-1-dependent cell transformation through direct binding of DJ-1 to PTEN. Int J Oncol 35: 1331-1341, 2009.

53. Markiewicz E, Ledran M and Hutchison CJ: Remodelling of the nuclear lamina and nucleoskeleton is required for skeletal muscle differentiation in vitro. J Cell Sci 118: 409-420, 2005

54. Wikman $\mathrm{H}$ and Kettunen E: Regulation of the G1/S phase of the cell cycle and alterations in the RB pathway in human lung cancer. Expert Rev Anticancer Ther 6: 515-530, 2006.

55. Smith RC, Branellec D, Gorski DH, Guo K, Perlman H, Dedieu JF, Pastore C, Mahfoudi A, Denèfle P, Isner JM and Walsh K: p21CIP1-mediated inhibition of cell proliferation by overexpression of the gax homeodomain gene. Genes Dev 11: 1674-1689, 1997.

56. Condorelli G, Aycock JK, Frati G and Napoli C: Mutated p21/ WAF/CIP transgene overexpression reduces smooth muscle cell proliferation, macrophage deposition, oxidation-sensitive mechanisms, and restenosis in hypercholesterolemic apolipoprotein E knockout mice. FASEB J 15: 2162-2170, 2001

57. Merched AJ and Chan L: Absence of p21Waf1/Cip1/Sdi1 modulates macrophage differentiation and inflammatory response and protects against atherosclerosis. Circulation 110 3830-3841, 2004.

58. Brader S and Eccles SA: Phosphoinositide 3-kinase signalling pathways in tumor progression, invasion and angiogenesis. Tumori 90: 2-8, 2004

59. Musumeci M, Maccari S, Corritore E, Massimi A, Stati T, Marano G and Catalano L: Signaling pathway-focused gene expression profiling in pressure overloaded hearts. Ann Ist Super Sanita 47: 290-295, 2011

60. Ouimet M: Autophagy in obesity and atherosclerosis: Interrelationships between cholesterol homeostasis, lipoprotein metabolism and autophagy in macrophages and other systems. Biochim Biophys Acta 1831: 1124-1133, 2013.

61. Yao PM and Tabas I: Free cholesterol loading of macrophages induces apoptosis involving the fas pathway. J Biol Chem 275: 23807-23813, 2000.

62. Waters SM, Coyne GS, Kenny DA and Morris DG: Effect of dietary n-3 polyunsaturated fatty acids on transcription factor regulation in the bovine endometrium. Mol Biol Rep 41: 2745-2755, 2014

63. Merched AJ, Williams E and Chan L: Macrophage-specific p53 expression plays a crucial role in atherosclerosis development and plaque remodeling. Arterioscler Thromb Vasc Biol 23: $1608-1614,2003$
64. Lee SJ, Park K, Ha SD, Kim WJ and Moon SK: Gleditsia sinensis thorn extract inhibits human colon cancer cells: the role of ERK1/2, G2/M-phase cell cycle arrest and p53 expression. Phytother Res 24: 1870-1876, 2010.

65. Lee SJ, Park SS, Kim WJ and Moon SK: Gleditsia sinensis thorn extract inhibits proliferation and TNF- $\alpha$-induced MMP-9 expression in vascular smooth muscle cells. Am J Chin Med 40: 373-386, 2012.

66. Lu Y, Li CS and Dong Q: Chinese herb related molecules of cancer-cell-apoptosis: a minireview of progress between Kanglaite injection and related genes. J Exp Clin Cancer Res 27: 31, 2008.

67. Li B, Zhao J, Wang CZ, et al: Ginsenoside Rh2 induces apoptosis and paraptosis-like cell death in colorectal cancer cells through activation of p53. Cancer Lett 301: 185-192, 2011.

68. Gali-Muhtasib H, Diab-Assaf M, Boltze C, et al: Thymoquinone extracted from black seed triggers apoptotic cell death in human colorectal cancer cells via a p53-dependent mechanism. Int J Oncol 25: 857-866, 2004.

69. Lee SJ, Kim HM, Cho YH, et al: Aqueous extract of Magnolia officinalis mediates proliferative capacity, p21WAF1 expression and TNF- $\alpha$-induced NF- $\mathrm{KB}$ activity in human urinary bladder cancer 5637 cells; involvement of p38 MAP kinase. Oncol Rep 18: 729-736, 2007

70. Dong LH, Wen JK, Miao SB, et al: Baicalin inhibits PDGF-BBstimulated vascular smooth muscle cell proliferation through suppressing PDGFR $\beta$-ERK signaling and increase in p27 accumulation and prevents injury-induced neointimal hyperplasia. Cell Res 20: 1252-1262, 2010.

71. Way TD, Lee JC, Kuo DH, et al: Inhibition of epidermal growth factor receptor signaling by Saussurea involucrata, a rare traditional Chinese medicinal herb, in human hormone-resistant prostate cancer PC-3 cells. J Agric Food Chem 58: 3356-3365, 2010.

72. Hahm ER and Singh SV: Honokiol causes G0-G1 phase cell cycle arrest in human prostate cancer cells in association with suppression of retinoblastoma protein level/phosphorylation and inhibition of E2F1 transcriptional activity. Mol Cancer Ther 6: 2686-2695, 2007.

73. Tao R, Lu L, Zhang R, Hu J, Ni J and Shen W: Triptolide inhibits rat vascular smooth muscle cell proliferation and cell cycle progression via attenuation of ERK1/2 and Rb phosphorylation. Exp Mol Pathol 90: 137-142, 2011.

74. Shan BE, Zeki K, Sugiura T, Yoshida Y and Yamashita U: Chinese medicinal herb, Acanthopanax gracilistylus, extract induces cell cycle arrest of human tumor cells in vitro. Jpn J Cancer Res 91: 383-389, 2000.

75. Xiao XY, Hao M, Yang XY, et al: Licochalcone A inhibits growth of gastric cancer cells by arresting cell cycle progression and inducing apoptosis. Cancer Lett 302: 69-75, 2011

76. Kametani S, Oikawa T, Kojima-Yuasa A, et al: Mechanism of growth inhibitory effect of cape aloe extract in ehrlich ascites tumor cells. J Nutr Sci Vitaminol (Tokyo) 53: 540-546, 2007.

77. Yang P, Cartwright C, Chan D, Vijjeswarapu M, Ding J and Newman RA: Zyflamend-mediated inhibition of human prostate cancer PC3 cell proliferation: effects on $12-\mathrm{LOX}$ and $\mathrm{Rb}$ protein phosphorylation. Cancer Biol Ther 6: 228-236, 2007.

78. Liu H, Zang C, Emde A, et al: Anti-tumor effect of honokiol alone and in combination with other anti-cancer agents in breast cancer. Eur J Pharmacol 591: 43-51, 2008.

79. Yang JY, Della-Fera MA, Rayalam S and Baile CA: Enhanced effects of xanthohumol plus honokiol on apoptosis in 3T3-L1 adipocytes. Obesity (Silver Spring) 16: 1232-1238, 2008.

80. Roy S, Yu Y, Padhye SB, Sarkar FH and Majumdar AP: Difluorinated-curcumin (CDF) restores PTEN expression in colon cancer cells by down-regulating miR-21. PLoS One 8: e68543, 2013

81. Yoshida H, Okumura N, Kitagishi Y, Nishimura Y and Matsuda S: Ethanol extract of rosemary repressed PTEN expression in K562 culture cells. Int J Appl Boil Pharm Technol 2: 316-322, 2011

82. Bosviel R, Dumollard E, Déchelotte P, Bignon YJ and BernardGallon D: Can soy phytoestrogens decrease DNA methylation in BRCA1 and BRCA2 oncosuppressor genes in breast cancer? OMICS 16: 235-244, 2012.

83. Kobayashi K, Nagata E, Sasaki K, Harada-Shiba M, Kojo S and Kikuzaki H: Increase in secretory sphingomyelinase activity and specific ceramides in the aorta of apolipoprotein $\mathrm{E}$ knockout mice during aging. Biol Pharm Bull 36: 1192-1196, 2013. 